\title{
Uniportal video-assisted thoracoscopic thymectomy: the glove-port with carbon dioxide insufflation
}

\author{
Majed Refai ${ }^{1}$, Diego Gonzalez-Rivas ${ }^{2,3}$, Gian Marco Guiducci ${ }^{1}$, Alberto Roncon ${ }^{1}$, Michela Tiberi $^{1}$, \\ Francesco Xiumè ${ }^{1}$, Michele Salati ${ }^{1}$, Marco Andolfi ${ }^{1}$ \\ ${ }^{1}$ Unit of Thoracic Surgery, AOU Ospedali Riuniti, Ancona, Italy; ${ }^{2}$ Department of Thoracic Surgery, Coruña University Hospital, Coruña, Spain; \\ ${ }^{3}$ Department of Thoracic Surgery, Shanghai Pulmonary Hospital, Shanghai 200082, China \\ Contributions: (I) Conception and design: M Refai, M Andolfi, D Gonzalez-Rivas; (II) Administrative support: None; (III) Provision of study materials \\ or patients: M Tiberi, GM Guiducci, A Roncon; (IV) Collection and assembly of data: M Andolfi, M Tiberi; (V) Data analysis and interpretation: M \\ Refai, M Andolfi; (VI) Manuscript writing: All authors; (VII) Final approval of manuscript: All authors. \\ Correspondence to: Majed Refai, MD. Chief, Section of Minimally Invasive Thoracic Surgery, Unit of Thoracic Surgery, AOU Ospedali Riuniti, \\ Ancona, Italy. Email: majedit@yahoo.com.
}

Background Since 2004, uniportal video-assisted thoracic surgery (VATS) approach was progressively widespread and also applied in the treatment of thymoma, with promising results. We report the first series of patients who undergone uniportal VATS thymectomy using a homemade glove-port with carbon dioxide $\left(\mathrm{CO}_{2}\right)$ insufflation. The aim of this article is to analyze the safety and feasibility to perform an extended thymectomy (ET).

Methods: A prospective, single-centre, short-term observational study including patients with mediastinal tumours undergoing scheduled uniportal VATS resection using a glove-port with $\mathrm{CO}_{2}$. Operations were performed through a single incision of $3.5 \mathrm{~cm}$ at the fifth intercostal space, right or left anterior axillary line. A $5 \mathrm{~mm}-30^{\circ}$ camera and working instruments were employed through a glove-port with $\mathrm{CO}_{2}$.

Results: Thirty-eight patients (20 men; mean age 61.6 years) underwent ET between September 2016 and October 2019. Thirteen patients had a history of Myasthenia Gravis (MG) with thymoma and 8 had incidental findings of thymoma. Additionally, 8 mediastinal cysts and 9 thymic hyperplasia were included. Mean diameter of the tumor was $5.1 \mathrm{~cm}$ (range, 1.6-14 cm) and mean operation time was 143 minutes. Mean postoperative drainage duration and hospital stay were 2.3 and 4.3 days, respectively. Mean blood loss was $41 \mathrm{~mL}$. There was no occurrence of surgical morbidity or mortality. During the follow-up period (1-36 months), no recurrence was noted.

Conclusions: Our results suggest that uniportal VATS thymectomy through glove-port and $\mathrm{CO}_{2}$ is safe and feasible procedure, even with large thymomas. Furthermore, the glove-port system represents a valid, cheap and widely available alternative to the commercial devices usually adopted in thoracic surgery.

Keywords: Glove-port; uniportal video-assisted thoracoscopic thymectomy; thymectomy; video-assisted thoracic surgery (VATS); myasthenia gravis (MG)

Submitted Dec 20, 2019. Accepted for publication Mar 27, 2020.

doi: $10.21037 /$ gs-19-521

View this article at: http://dx.doi.org/10.21037/gs-19-521

\section{Introduction}

The spread of video-assisted thoracic surgery (VATS) started in the early 1990s (1), when surgeons began using this approach to perform major thoracic surgery including mediastinal tumour resection. Indeed, patients who underwent VATS approach showed better postoperative outcome, shorter length of stay and better cosmetic results compared with conventional open access (2). Since 2004, uniportal VATS resections have become progressively widespread worldwide (3). Because of the progressive 
development of thoracoscopic surgical instruments and endoscopic techniques, uniportal VATS approach has also been broadly applied in the treatment of thymoma patients, having shown promising results and gradually replacing median sternotomy (4). However, there is a paucity of published data with respect to uniportal VATS thymectomy (5-7) and to date, this is the first time that the use of a homemade glove-port system is reported in thoracic surgery permitting the use of carbon dioxide $\left(\mathrm{CO}_{2}\right)$ insufflation that guarantees better exposure and dissection of the thymus.

The aim of this article is to analyze the safety and feasibility of single incision glove-port VATS to perform extended thymectomy (ET).

\section{Methods}

This prospective, single-centre short-term observational study was carried out at the Unit of Thoracic Surgery, AOU Ospedali Riuniti Ancona. Consenting patients scheduled to undergo elective ET were enrolled. Written informed consent was obtained from all patient. All procedures were performed and supervised by a single surgeon (RM).

The preoperative workup included detailed history, accurate physical examination, complete blood count, tests to diagnose myasthenia gravis (MG) (autoantibodies to the muscle nicotinic acetylcholine receptor, Tensilon test or electromyography), neurological evaluation, 12-lead electrocardiogram, spirometry, computed tomography (CT) and 18FDG-Positron emission tomography (PET-CT).

In our study exclusion criteria were:

(I) All patients with mediastinal tumour invasion of adjacent vascular vessels (for instance the superior vena cava and the innominate veins) documented on CT scan;

(II) Previous exposure of the mediastinum to radiotherapy.

For both MG patients and non-MG patients, we performed an ET, defined as the resection of the thymus gland, as well as the pericardial adipose tissue from the right phrenic nerve to the left one. All surgical procedures were performed under general anaesthesia with selective onelung ventilation and patients underwent a single glove-port VATS approach. Postoperative intensive care was required in MG patients. All other patients were scheduled to be extubated in the operating room (OR) and managed in our thoracic unit ward. All resected specimens were sent with different landmarks indicating the correct orientation. Pathologic staging and histologic typing were established according to the World Health Organization classification and Masaoka stage.

From the first postoperative day, all patients received daily physiotherapy, which included deep breathing exercises, incentive spirometry, supported coughing and early mobilisation.

\section{Glove port technique}

We prepared the glove port with simple and inexpensive instruments that are widely available: a size 7 latex sterile surgical glove, a double-ring wound protector, wound closure strips, 1-0 silk ties and three 5-mm trocar (Figure 1A). After performing 3 holes of $2-3 \mathrm{~mm}$ on the glove fingertip, silicon trocars were placed into the thumb, third and fifth fingers of the glove by 1-0 silk ties and wound closure strips, in order to minimize conflicts between instruments during surgery (Figure 1B). After that, the glove-system was fixed to the retractor outer ring, rolling up the wrist portion of the glove on the flexible ring (Figure $2 A$ ).

The thumb-trocar was connected to a carbon dioxide gas insufflator and used for the $30^{\circ}, 5 \mathrm{~mm}$ camera. In the other two trocars, we inserted thoracoscopic instruments (Figure 2B). The additional two trocars in the second and fourth fingers of the glove were placed as necessary (Figure 2C).

\section{Surgical procedure}

The patient was conducted into the OR and general anesthesia was performed using a left double lumen oro-tracheal tube checked by a flexible bronchoscope. Therefore, the patient was positioned in a $30^{\circ}$ semi-supine position with a silicon cushion inserted below the right hemithorax and the ipsilateral arm was abducted in order to expose the axilla (Figure $3 A$ ). The surgical field was then prepped. Of 38 surgical procedures, 29 were performed using a right-sided approach, due to the relatively large space in the right chest cavity (because of the absence of the heart) and the anatomical landmarks consisting of the superior vena cava, the phrenic nerve and the innominate vein. Instead, 9 patients underwent left-sided approach, due to the tumour location on the left of the median line.

A single incision of $3-4 \mathrm{~cm}$ at the fifth intercostal space, anterior axillary line, was created in all cases (Figure 3B). After connecting the glove-system to the wound protector, we started insufflating $\mathrm{CO}_{2}$ with a $6 \mathrm{~L} / \mathrm{min}$ flow and 8 $\mathrm{mmHg}$ (the level was regulated in accordance with the anesthesiologist depending on the hemodynamic response 

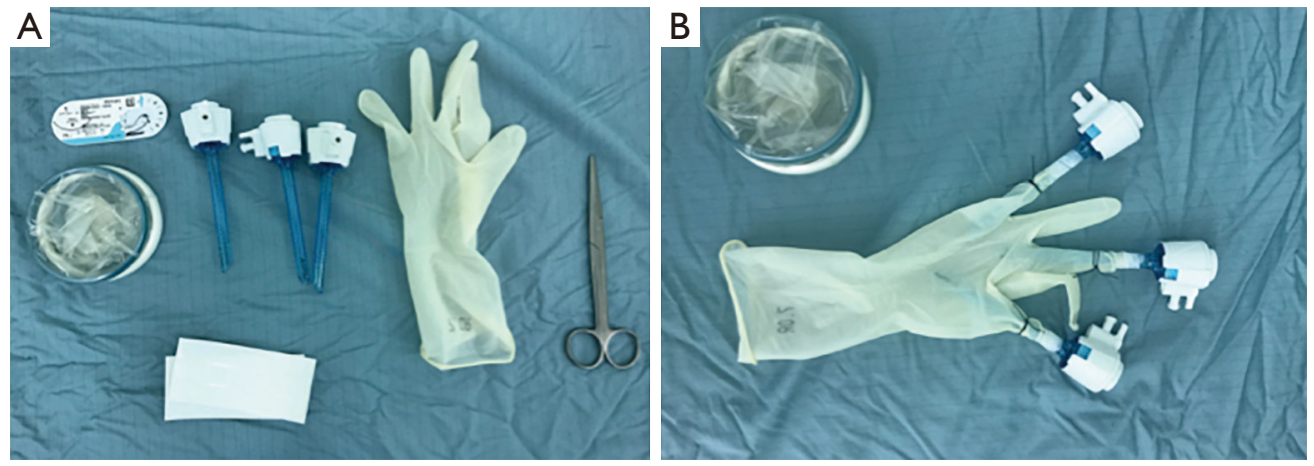

Figure 1 Glove-port materials. (A) Instruments needed to made the glove system: a size 7 latex sterile surgical glove, a double-ring wound protector, 1-0 silk ties, wound closure strips and three 5-mm trocar; (B) the glove-port system: silicon trocars were placed into the thumb, third and fifth fingers of the glove.
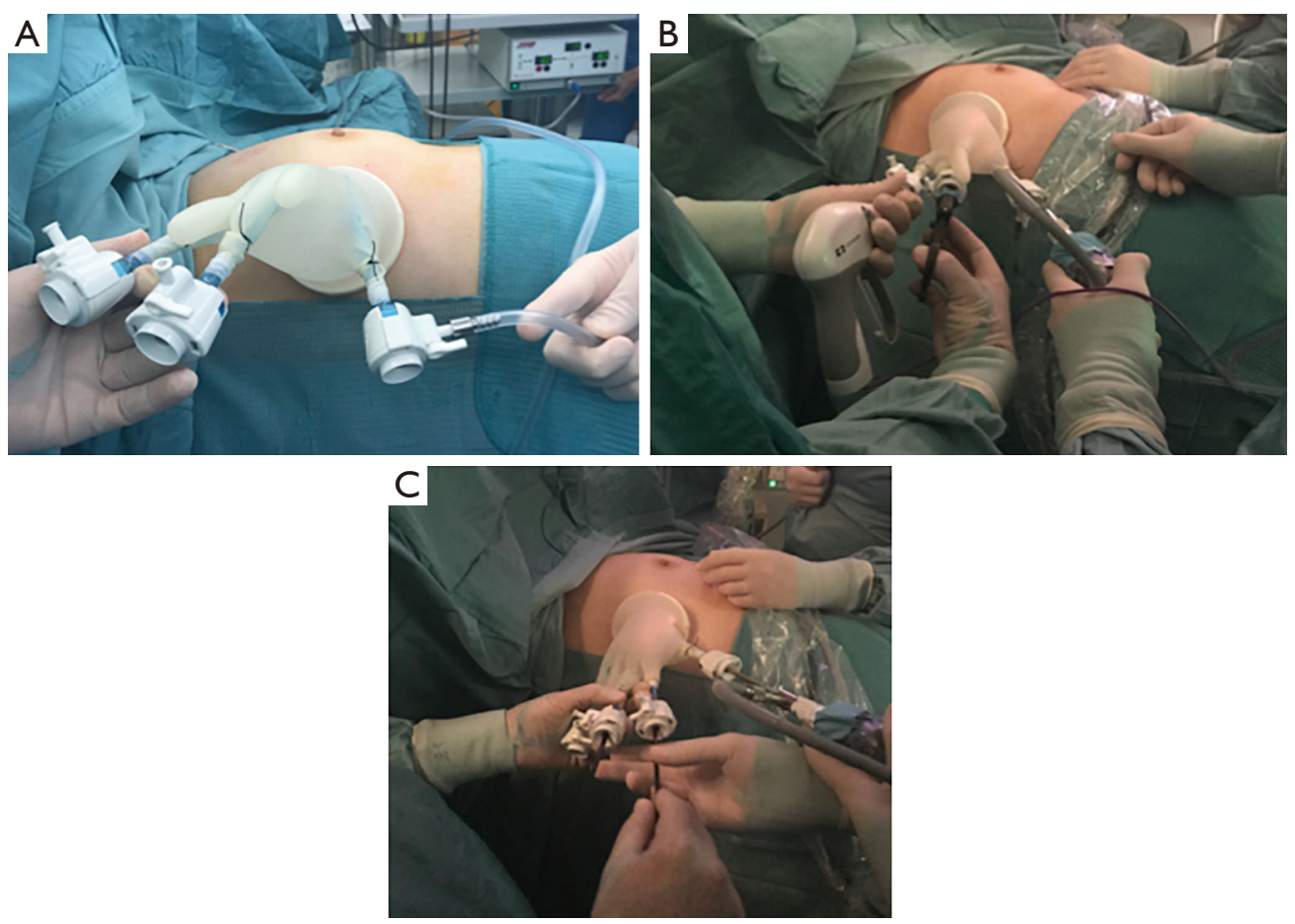

Figure 2 Glove-port instruments insertion. (A) The glove-system fixed to the retractor outer ring; (B) the glove-system with thoracoscopic instruments inserted; $(\mathrm{C})$ additional two trocars in the second and fourth fingers of the glove can be placed as necessary.

and hematic $\mathrm{CO}_{2}$ level), allowing the operator and assistant, both posteriorly to the patient, to dissect the fat plane more easily and to gain better access to the bilateral thymic horns. Moreover, $\mathrm{CO}_{2}$ provides more space to dissect large masses.

Dissection started from caudal to cranial along the phrenic nerve and lateral to medial until reaching the contralateral pleura and phrenic nerve. We always used an Energy Device for removing pericardial adipose tissue from the phrenic nerves in order to avoid nerve damage. Thymectomy was then performed proceeding along the left innominate vein and dividing the thymic veins with the use of haemoclips or by the use of the energy device. The specimen was finally placed in an endobag and taken out of the thorax after removing the glove-system. In all cases, only 

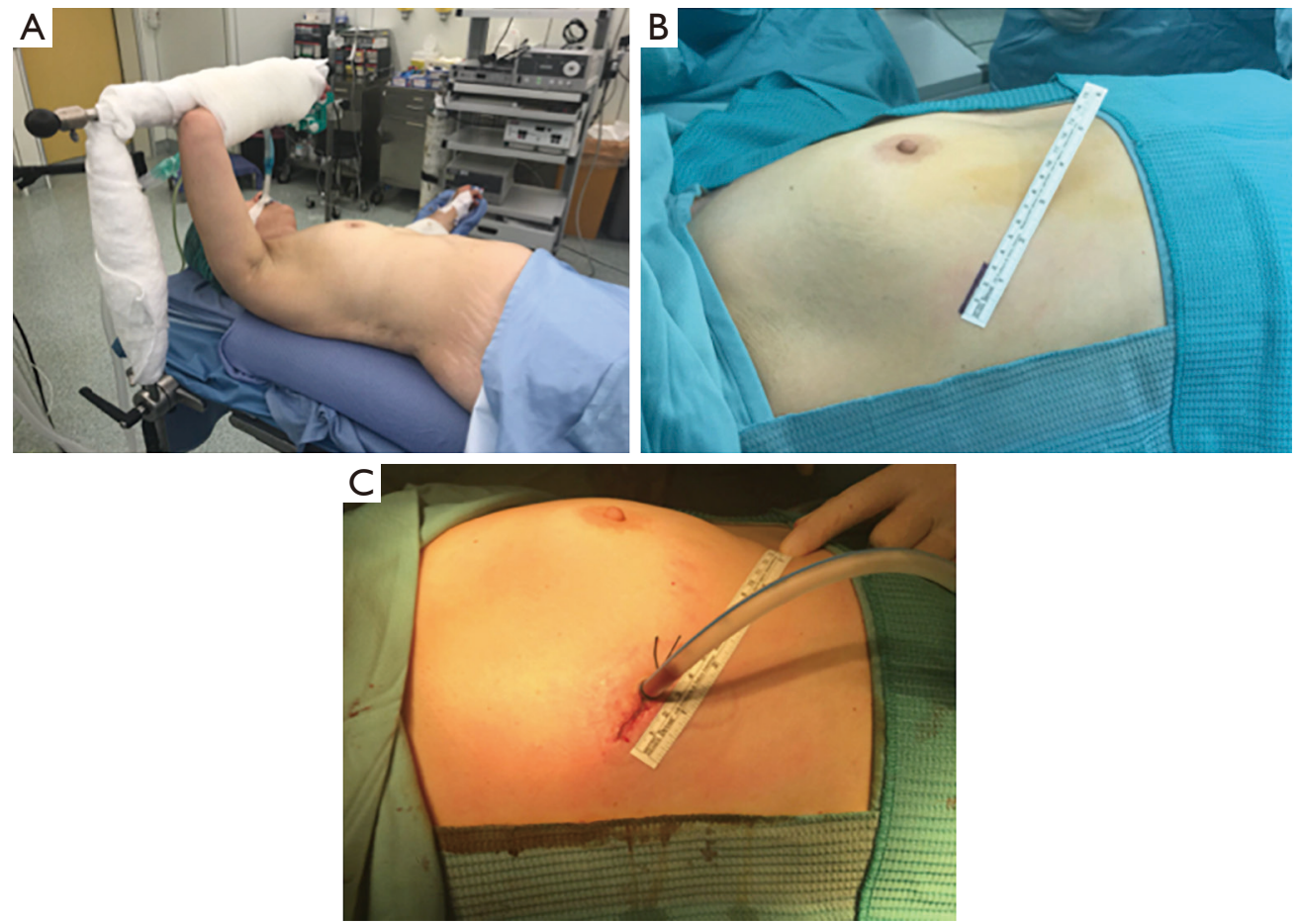

Figure 3 Uniportal VATS approach. (A) $30^{\circ}$ semi-supine position with a silicon pilot inserted below the right hemithorax and the ipsilateral arm abducted; (B) single incision of $3 \mathrm{~cm}$ at the fifth intercostal space, right anterior axillary line; (C) a 24 Ch chest tube through the port collected with electronic drainage system. VATS, video-assisted thoracic surgery.

one $24 \mathrm{Ch}$ chest tube was placed in the anterior mediastinum through the port collected with electronic drainage system (Figure 3C), although the contralateral pleural cavity was occasionally opened during the surgical procedure. Landmarks were positioned in order to define the correct orientation of the surgical specimen. Intraoperative pain was controlled infiltrating three intercostal spaces (IV, $\mathrm{V}$ and VI intercostal spaces) with Naropina $7.5 \%$ at the end of the operation under thoracoscopic vision.

\section{Results}

Thirty-eight consecutive patients $(20$ men and 18 women, mean age of 61.6 years) were enrolled in the study group between September 2016 and October 2019. No patients needed to convert to multiport VATS approach, thoracotomy or sternotomy. No intraoperative complications were recorded and no problem concerning contralateral ventilation occurred when the pleural cavity was occasionally opened. Indeed, neither hemodynamic response nor hematic $\mathrm{CO}_{2}$ level underwent significant changes during these events, allowing to continuate the procedure insufflating $\mathrm{CO}_{2}$.

Age, gender, pulmonary function tests, operation time, blood loss, incision length, duration of chest tube drainage and length of hospital stay are listed in Table 1. Of the thirty-eight patients, 13 had a history of refractory MG with thymoma and 8 had incidental findings of thymoma without MG. Additionally, 8 mediastinal cysts and 9 thymic follicular hyperplasia were included in the study. The mean forced expiratory volume in one second, forced vital capacity and diffusing capacity of the lung for carbon monoxide were $99 \%, 104 \%$ and $84 \%$ respectively. All patients received ET.

The pathologic characteristics of the tumours are collected in Table 2. The mean diameter of the resected tumor was $5.1 \mathrm{~cm}$ (range: 1.6 to $14 \mathrm{~cm}$ ) and mean operation time was 143 minutes. The mean postoperative drainage duration and length of hospital stay were 2.3 and 4.3 days, respectively. The mean of blood loss was $41 \mathrm{~mL}$. There was no occurrence of surgical morbidity or mortality in the study group. During the follow-up period (1-36 months), no recurrence of the tumour was noted and MG therapy has not changed. 
Table 1 Characteristics of the enrolled patients

\begin{tabular}{lc}
\hline Characteristic & Total $(\mathrm{n}=38)$ \\
\hline Age (yrs) & $61.6[19-79]$ \\
Males & 20 \\
FEV1 (\%) & 99 \\
FVC (\%) & 104 \\
DLCO (\%) & 84 \\
Operation time (min) & 143 \\
Blood loss (mL) & 41 \\
Incision length (cm) & 3.5 \\
Chest tube (days) & 2.3 \\
Hospital stay (days) & 4.3 \\
\hline
\end{tabular}

FEV1, forced expiratory volume in one second; FVC, forced vital capacity; DLCO, diffusing capacity of the lung for carbon monoxide.

\section{Discussion}

We present the first case-series in literature reporting the use of a single glove-port VATS approach to perform ET.

Several surgical teams started to use the VATS approach for mediastinal tumour resection more than 20 years ago, when the technique become widely accepted as an effective alternative to the traditional open approach, ensuring an effective treatment for both Masaoka stage I and II thymoma $(6,8)$.

Therefore, in addition to the other minimal invasive methods such as transcervical (9) and sub-xyphoid approach (10), VATS resection became progressively widespread worldwide due to its benefits, including less postoperative pain, less blood loss, better outcome of patients, shorter length of stay and better cosmetic results compared to conventional open surgery $(2,5)$. Different VATS approaches were described: unilateral multi-port VATS approach (8), bilateral multi-port VATS approach (11) and single-port VATS approach $(3,12)$. To date, although no consensus has been universally reached with regard to the gold standard surgical approach (5), most surgeons adopt unilateral three-port VATS approach. However recently some authors demonstrated that uniportal VATS for limited or ET may be a promising and safe approach with regard to short-term clinical outcome $(4,7,12,13)$.

Our initial experience of 38 consecutive patients who underwent uniportal VATS thymectomy provided results
Table 2 The pathologic characteristics of the mediastinal lesions

\begin{tabular}{lc}
\hline Pathological diagnosis & Total $(\mathrm{n}=38)$ \\
\hline Thymoma & 21 \\
Thymoma A & 3 \\
Thymoma AB & 9 \\
Thymoma B1 & 1 \\
Thymoma B2 & 5 \\
Thymoma B3 & 3 \\
Mediastinal cyst & 8 \\
Thymic follicular hyperplasia & 9 \\
\hline
\end{tabular}

comparable to those previously published in literature $(4,7)$, confirming that a single glove-port approach with $\mathrm{CO}_{2}$ represents a safe and feasible procedure even for very large thymomas.

Indeed, from our preliminary results and experience, we deduced that well-encapsulated tumours are ideal for the uniportal VATS approach even if they are $>5 \mathrm{~cm}$ of diameter. In particular, we suggest a right-sided approach for its benefits deriving from the anatomic landmarks and the absence of the heart.

Furthermore, the use of $\mathrm{CO}_{2}$ insufflation may ease the pulmonary collapse and the dissection phase of the fat plane, exploiting the iatrogenic pneumomediastinum.

To our knowledge this is the first case-series reporting the use of a glove-port system in thoracic surgery.

Indeed, authors who used the single-port technique to perform limited or ET, usually adopted a commercial singleport device (13) increasing the costs of surgery and limiting the instrument's insertion. We demonstrated that a glovesystem port may be both an effective and cost-effective device also in thoracic surgery, allowing the operator to reduce the conflict of the thoracoscopic instruments and to add up to 5 surgical tools as well as previously described in laparoendoscopic surgery.

Indeed, Park was the first to publish in 2009 the use of a homemade single-port device in a child reporting a case of a laparoendoscopic nephrectomy (14).

Since then, this novel, self-made, and inexpensive single-port device was adopted by numerous authors who exploited its several advantages in laparoendoscopic surgery: it is extremely cheaper than the other commercial singleport device; it is easy to make and widely available in the $\mathrm{OR}$; it does not require curved laparoscopic instruments, 
which increase the cost of surgery and reduce the working space; and it can be easily and rapidly removed (15-18). Furthermore, exploiting the flexibility of the glove, the conflicts between instruments is significantly reduced, maintaining the quality of medical care.

We found only one limitation of this glove-system: the opening of the port is not visible, and thus instrument insertion is not as smooth as with a commercialized port, requiring more attention to avoid piercing of the glove or damaging the skin. However, this criticism can be easily overcome either by feeling the opening for insertion with the hand or drawing back the camera inside the glove to drive the insertion of the instrument.

Our study has some limitations: this is a single centre pathophysiology driven clinical study, the study time was short, the number of cases was limited, and hence it cannot fully elucidate the independent prognostic impact of the findings.

Regarding the occurrence of postoperative MG or disease-free survival, our cohort follow-up time is too short to define the impact of uniportal VATS approach on oncological outcome. Further evaluations are needed to define its therapeutic role and prospective comparative trials with three-port or other less-invasive surgical techniques, are warranted to evaluate the best approach for the management of mediastinal tumours.

In conclusion, our study showed for the first time that single glove port VATS with $\mathrm{CO}_{2}$ insufflation for mediastinal mass resection is safe and feasible and may be used as an alternative to the traditional VATS resections; however, longer term follow-up is needed in order to validate the oncological outcome.

Furthermore, the glove-port system represents a valid, inexpensive and widely available alternative to the commercial devices usually adopted in thoracic surgery.

\section{Acknowledgments}

Funding: None.

\section{Footnote}

Conflicts of Interest: All authors have completed the ICMJE uniform disclosure form (available at http://dx.doi. org/10.21037/gs-19-521). The authors have no conflicts of interest to declare.

Ethical Statement: The authors are accountable for all aspects of the work in ensuring that questions related to the accuracy or integrity of any part of the work are appropriately investigated and resolved. The study protocol was approved by the local regional ethics committee and was performed in accordance with the ethical standards of the Declaration of Helsinki (as revised in 2013). All patients gave their informed consent prior to their inclusion in the study.

Open Access Statement: This is an Open Access article distributed in accordance with the Creative Commons Attribution-NonCommercial-NoDerivs 4.0 International License (CC BY-NC-ND 4.0), which permits the noncommercial replication and distribution of the article with the strict proviso that no changes or edits are made and the original work is properly cited (including links to both the formal publication through the relevant DOI and the license). See: https://creativecommons.org/licenses/by-nc-nd/4.0/.

\section{References}

1. Hazelrigg SR, Nunchuck SK, LoCicero J 3rd. Video Assisted Thoracic Surgery Study Group data. Ann Thorac Surg 1993;56:1039-43.

2. Refai M, Andolfi M, Sabbatini A. Physiopathology aspects of anatomical video-assisted thoracic surgery resections: current status and prospects of development. J Vis Surg 2017;3:161.

3. Gonzalez-Rivas D, Paradela M, Fieira E, et al. Singleincision video-assisted thoracoscopic lobectomy: initial results. J Thorac Cardiovasc Surg 2012;143:745-7.

4. Wu CF, Gonzalez-Rivas D, Wen CT, et al. Single-port video-assisted thoracoscopic mediastinal tumour resection. Interact Cardiovasc Thorac Surg 2015;21:644-9.

5. Ng CS, Wan IY, Yim AP. Video-assisted thoracic surgery thymectomy: the better approach. Ann Thorac Surg 2010;89:S2135-41.

6. Cheng YJ, Kao EL, Chou SH. Videothoracoscopic resection of stage II thymoma: prospective comparison of the results between thoracoscopy and open methods. Chest 2005;128:3010-2.

7. Wu CY, Heish MJ, Wu CF. Single port VATS mediastinal tumor resection: Taiwan experience. Ann Cardiothorac Surg 2016;5:107-11.

8. Yim AP, Kay RL, Ho JK. Video-assisted thoracoscopic thymectomy for myasthenia gravis. Chest 1995;108:1440-3.

9. Zieliński M, Kuzdzał J, Szlubowski A, et al. Transcervical- 
subxiphoid-videothoracoscopic "maximal" thymectomy-operative technique and early results. Ann Thorac Surg 2004;78:404-9.

10. Zielinski M, Czajkowski W, Gwozdz P, et al. Resection of thymomas with use of the new minimally-invasive technique of extended thymectomy performed through the subxiphoid-right video-thoracoscopic approach with double elevation of the sternum. Eur J Cardiothorac Surg 2013;44:e113-9.

11. Shiono H, Kadota Y, Hayashi A, et al. Comparison of outcomes after extended thymectomy for myasthenia gravis: bilateral thoracoscopic approach versus sternotomy. Surg Laparosc Endosc Percutan Tech 2009;19:424-7.

12. Gonzalez-Rivas D, Wu CF, de la Torre M. Uniportal video-assisted thoracoscopic thymectomy and resection of a giant thymoma in a patient witness of Jehova. J Thorac Dis 2017;9:E556-9.

13. Scarci M, Pardolesi A, Solli P. Uniportal video-assisted thoracic surgery thymectomy. Ann Cardiothorac Surg 2015;4:567-70.

Cite this article as: Refai M, Gonzalez-Rivas D, Guiducci GM, Roncon A, Tiberi M, Xiumè F, Salati $M$, Andolfi $M$. Uniportal video-assisted thoracoscopic thymectomy: the gloveport with carbon dioxide insufflation. Gland Surg 2020;9(4):879885. doi: $10.21037 /$ gs-19-521
14. Park YH, Kang MY, Jeong MS, et al. Laparoendoscopic single-site nephrectomy using a homemade single-port device for single-system ectopic ureter in a child: initial case report. J Endourol 2009;23:833-5.

15. Jeon $\mathrm{HG}$, Jeong $\mathrm{W}$, Oh $\mathrm{CK}$, et al. Initial experience with 50 laparoendoscopic single site surgeries using a homemade, single port device at a single center. J Urol 2010;183:1866-71.

16. Di Saverio S, Mandrioli M, Birindelli A, et al. SingleIncision Laparoscopic Appendectomy with a Low-Cost Technique and Surgical-Glove Port: "How To Do It" with Comparison of the Outcomes and Costs in a Consecutive Single-Operator Series of 45 Cases. J Am Coll Surg 2016;222:e15-30.

17. Lee SM, Hwang GS, Lee DS. Single-incision laparoscopic appendectomy using homemade glove port at low cost. J Minim Access Surg 2016;12:124-8.

18. Joshi HM, Gosselink MP, Adusumilli S, et al. Single incision glove port laparoscopic colorectal cancer resection. Ann R Coll Surg Engl 2015;97:204-7. 